\title{
Is Trade in Permits Good for the Environment?
}

\author{
Harvey E. Lapan ${ }^{1} \cdot$ Shiva Sikdar ${ }^{2}$
}

Accepted: 5 December 2017 / Published online: 14 December 2017

(C) The Author(s) 2017. This article is an open access publication

\begin{abstract}
We analyze the impact of trade in emission permits on environmental policy when countries trade a differentiated good. Pollution is always higher with tradable permits as compared to the case where permits are not internationally tradable. If pollution is a pure global public bad, i.e., the marginal damage from transboundary pollution is the same as that from local pollution, the permit price under trade equals the domestic marginal damage from own emissions. If pollution is not a pure global public bad, i.e., the marginal damage from transboundary pollution is less than that from local pollution, trade results in a permit price lower than the domestic marginal damage from own emissions-pollution is higher under trade relative to autarky. Regardless of the nature of transboundary pollution, the permit price (equivalent pollution tax) is lower and pollution is higher with internationally tradable permits than with nontradable permits.
\end{abstract}

Keywords Emission permit trade $\cdot$ Strategic environmental policy $\cdot$ Leakage · Intra-industry trade

JEL Classification Q56 · F18 $\cdot \mathrm{H} 23 \cdot \mathrm{Q} 58$

We are thankful to two anonymous referees for their comments and suggestions, which significantly improved the paper. We also thank participants at the Annual Conference on Contemporary Issues in Development Economics at Jadavpur University, India for helpful comments. The usual disclaimer applies.

Electronic supplementary material The online version of this article (https://doi.org/10.1007/s10640017-0202-z) contains supplementary material, which is available to authorized users.

Shiva Sikdar

shivasikdar@gmail.com

Harvey E. Lapan

hlapan@iastate.edu

1 Department of Economics, Iowa State University, 283 Heady Hall, Ames, IA 50011, USA

2 Keele Management School, Keele University, Darwin Building, Keele ST5 5BG, UK 


\section{Introduction}

Emission permit trading is supposed to achieve efficiency by equalizing marginal abatement costs across polluters. The initial success of the $\mathrm{US} \mathrm{SO}_{2}$ trading system bears testimony to this, which was instrumental in shaping the EU Emission Trading System (ETS), a $\mathrm{CO}_{2}$ capand-trade system adopted in 2003 (Schmalensee and Stavins 2013). The latter is, however, different-the European Commission determined the participating sectors, but individual countries could initially set their permit supplies. Using national allocation plans (NAPs), ${ }^{1}$ countries chose the fraction of their national permit limit allocated to participating sectors (see, for instance, Kruger et al. 2007; Antoniou et al. 2014). When permit trade occurs between countries rather than firms, it is possible that the number of permits on the international permit market are not fixed by some supranational agency. Then, strategic considerations imply that efficiency may not be achieved. Apart from terms of trade motives, countries can distort environmental policies to reduce leakage and to generate additional revenue from selling permits abroad. We analyze the impact of permit trade across countries on pollution when the above strategic incentives are present. The importance of this in a wider context is highlighted by Kruger et al. (2007): for the different Kyoto signatories, "it is clear that the degree of supranational authority is much lower than in the EU ETS". Along similar lines, Holtsmark and Sommervoll (2012) note that "the national emission targets in the Copenhagen Accord, which have been leading in subsequent negotiations, were quantified by individual governments after the Copenhagen meetings. Hence, those targets are not the result of negotiations and are therefore unlikely to maximize joint welfare as commonly assumed in the literature".

We model intra-industry trade in goods along with trade in emission permits when countries strategically choose environmental policies. ${ }^{2}$ We find that internationally tradable permits always result in higher pollution as compared to nontradable permits.

Copeland and Taylor (1995) and Lapan and Sikdar (2011) find that, with inter-industry trade, nontradable and tradable permits result in the same outcome when pollution is a pure global public bad; the latter paper also shows that tradable permits result in higher pollution when pollution is not a pure global public bad. Antoniou et al. (2014) show, using a symmetric Brander-Spencer type model in which countries export the same good to a third market and pollution is a pure global public bad, that permit trade results in lower emissions relative to nontradable permits. ${ }^{3}$ These papers, however, do not consider intra-industry trade. Empirical evidence suggest that a significant proportion of trade is intra-industry trade in similar goods between similar countries (Grubel and Lloyd 1975; Tharakan 1984; Bernhofen 1999).

Other papers considering intra-industry trade and pollution policy include Benarroch and Weder (2006), Fung and Maechler (2007), Gürtzgen and Rauscher (2000), Haupt (2006) and

\footnotetext{
${ }^{1}$ In phases 1 (2005-2007) and 2 (2008-2012), members submitted their NAPs to be approved by the European Commission; the Commission did require some countries to change their plans. In phase 3 (2013-2020), an EU-wide emissions cap replaced the previous system of national caps. See, for instance, http://ec.europa.eu/ clima/policies/ets/pre2013/nap/index_en.htm.

${ }^{2}$ Intra-industry trade is said to occur when countries simultaneously export and import similar products produced in the same industry (see Grubel and Lloyd 1975) as opposed to inter-industry trade where countries export and import goods produced in different industries.

${ }^{3}$ Godal and Holtsmark (2011) show that the efficiency gains from international permit trade can be lost if governments use additional emissions tax/subsidy. See Carbone et al. (2009) for a CGE model analyzing the impact of international permit trade. Related papers analyzing international permit trade, but in the absence of goods trade, include the following. Helm (2003) finds that trade in permits can have ambiguous effects on pollution, while Holtsmark and Sommervoll (2012) show that permit trade reduces efficiency and increases pollution. Dijkstra et al. (2011) find that welfare gains are possible due to trade in permits.
} 
Rauscher (1997), chapter 6. These papers, however, do not consider strategic policy setting with internationally tradable permits when leakage is possible.

In our model, which follows Lapan and Sikdar (2017), countries produce different varieties of a differentiated good along with a homogeneous good. Consumers' preference for different varieties of the good gives rise to intra-industry trade (see Armington 1969). Our model nests a number of possible scenarios. Pollution may be generated as a byproduct of the production of either or both goods. The setup also allows for substitutability between inputs that can reduce emissions, the possibility of abatement and having polluting as well as non-polluting inputs. There are both local and transboundary effects of pollution. Within this framework, we analyze the effect of trade in goods and emission permits. The goods terms of trade effect can increase or decrease emissions depending on the pattern of trade and the relative pollution intensities of the goods. The permit revenue effect tends to increase the number of permits issued due to the additional revenue generated from selling these permits in the international permit market. Leakage can also increase the number of permits issued under trade.

We find that permit trade equalizes the prices of different varieties of the differentiated good regardless of the number of permits issued by each country. Since a tradable permit issued in one country can be used in either country, there is no impact of issuing an additional permit on the terms of trade. With internationally nontradable permits (Lapan and Sikdar 2017), the terms of trade effect makes environmental policy stricter under trade. Hence, internationally tradable emission permits always result in higher pollution than nontradable permits due to the absence of the incentive to make pollution policy stricter to gain terms of trade advantage. Our finding points to the need for careful consideration in the push for international trade in emission permits. This applies even when pollution is a pure global public bad, in which case there is no incentive to underregulate pollution for additional permit revenues and hence, internationally tradable permits would seem to be advisable.

The model is presented in the next section; Sect. 3 analyzes strategic environmental policies with internationally tradable permits. Section 4 concludes. The "Appendix" contains a proof.

\section{The Model}

Consider intra-industry trade in goods along with trade in emission permits between two large countries, a home country and a foreign country (foreign variables are denoted by *). We specify assumptions such that our results are primarily driven by the strategic aspect of setting environmental policies. ${ }^{4}$

Different varieties, $X$ and $X^{*}$, of a differentiated good are produced only in the home country and the foreign country, respectively. A homogeneous good, $Y$, is produced in both countries. Home and foreign production possibility frontiers are, respectively:

$$
g(x, y, z ; \vec{V}) \geq 0 \text { and } g^{*}\left(x^{*}, y^{*}, z^{*} ; \vec{V}^{*}\right) \geq 0,
$$

where $g_{x}, g_{x^{*}}^{*}, g_{y}, g_{y^{*}}^{*}<0<g_{z}, g_{z^{*}}^{*}, g_{v_{i}}, g_{v_{i}^{*}}^{*} ; z\left(z^{*}\right)$ is home (foreign) emissions and $\vec{V}$ $\left(\vec{V}^{*}\right)$ is the vector of home (foreign) inputs. This specification of the production possibility function nests the case in which pollution is generated in either or both sectors. It allows

\footnotetext{
4 Opening a country to trade can lead to changes in environmental outcomes for other reasons. Trade can change the mix of goods produced in each country. How this affects pollution depends on the relative pollution intensities of the exportable and importable goods. Also, ignoring pollution and any other market failure, trade can raise real income levels and increase the demand for normal goods; thus, if a clean environment is a normal good, trade will affect environmental policy through this income effect.
} 
for the possibility of abatement, substitutability between different inputs that can reduce emissions, and having polluting as well as non-polluting inputs.

Let $c_{x}, c_{x^{*}}$ and $c_{y}\left(c_{x}^{*}, c_{x^{*}}^{*}\right.$ and $\left.c_{y}^{*}\right)$ denote consumption of $X, X^{*}$ and $Y$ in the home (foreign) country. Intra-industry trade in the differentiated good arises due to consumers' preference for both varieties of the differentiated good, which are imperfect substitutes (see Armington 1969; Lapan and Sikdar 2017). Preferences of the representative agents in the home and foreign countries are given by, respectively:

$$
\begin{aligned}
U\left(c_{x}, c_{x^{*}}, c_{y}, z, z^{*}\right) & =c_{y}+\Theta\left(c_{x}, c_{x^{*}}\right)-\psi\left(z, z^{*}\right) \text { and } \\
U^{*}\left(c_{x}^{*}, c_{x^{*}}^{*}, c_{y}^{*}, z^{*}, z\right) & =c_{y}^{*}+\Theta^{*}\left(c_{x}^{*}, c_{x^{*}}^{*}\right)-\psi^{*}\left(z^{*}, z\right),
\end{aligned}
$$

where $\Theta($.$) and \Theta^{*}($.$) are strictly concave functions, while \psi($.$) and \psi^{*}($.$) are strictly con-$ vex functions of their respective arguments; $\psi_{z}, \psi_{z^{*}}, \psi_{z}^{*}, \psi_{z^{*}}^{*}>0$. Total disutility from pollution, $\psi($.$) and \psi^{*}($.$) , consists of two components: disutility from domestic emissions,$ i.e., due to local pollution, and from the inflow of transboundary pollution from the other country. In the home country, for instance, the marginal disutility from own emissions (local pollution) is $\psi_{z}($.$) , while the marginal disutility from the inflow of transboundary pollution$ from the foreign country is $\psi_{z^{*}}($.$) . When pollution is a pure global public bad, \psi_{z}=\psi_{z^{*}}$, while $\psi_{z}>\psi_{z^{*}}$ when pollution is not a pure global public bad. The standard assumption for differentiated goods models, that $\Theta($.$) and \Theta^{*}($.$) are CES functions of their respective$ arguments, is subsumed in this setup.

Let $Y$ be the numeraire good, i.e., set the price of $Y, p_{y} \equiv 1$. Let $p$ and $p^{*}$ be the (world) prices of $X$ and $X^{*}$, respectively. Suppose $L$ and $L^{*}$ are the permits issued by the the he and foreign countries, respectively, while $\tau$ and $\tau^{*}$ are the permit prices in the home and foreign countries. The home country's GNP function is given by ${ }^{5}$ :

$$
R(p, \tau)=\max _{x, y, z}(p x+y-\tau z) \text { s.t. } g(x, y, z ; \vec{V}) \geq 0 \text {. }
$$

Given the externality, the home expenditure function is given by:

$$
\begin{array}{r}
e\left(p, p^{*}, u\right)=\min _{c_{x}, c_{x^{*}, c_{y}}\left(p c_{x}+p^{*} c_{x^{*}}+c_{y}\right) \text { s.t. } c_{y}+\Theta\left(c_{x}, c_{x^{*}}\right)-\psi\left(z, z^{*}\right) \geq u,} \\
\text { i.e., } e\left(p, p^{*}, u+\psi\left(z, z^{*}\right)\right)=\min _{c_{x}, c_{x^{*}, c_{y}}\left(p c_{x}+p^{*} c_{x^{*}}+c_{y}\right) \text { s.t. } c_{y}+\Theta\left(c_{x}, c_{x^{*}}\right) \geq u+\psi\left(z, z^{*}\right) .}
\end{array}
$$

The preferences in Eq. (1) imply that the optimal level of pollution is independent of income levels, i.e., $e_{u u}=e_{u^{*} u^{*}}^{*}=0$. This allows us to focus on strategic channels through which trade affects environmental outcomes that are not tied to changes in income. Since $\frac{\partial(\partial e / \partial z)}{\partial u}=\frac{\partial\left(e_{u} \psi_{z}\right)}{\partial u}=e_{u u} \psi_{z}, e_{u u}=0$ implies that the demand for cleaner environment (pollution/abatement) does not change with income. Also, the income elasticity of demand for the different varieties of the differentiated good, $X$ and $X^{*}$, is zero, i.e., $e_{p u}=e_{p^{*} u}=$ $e_{p u^{*}}^{*}=e_{p^{*} u^{*}}^{*}=0$. This simplifies our analysis, and if differentiated goods are the drivers of pollution, removes an indirect channel through which income effects would affect pollution.

\footnotetext{
5 In autarky (or when emission permits are not internationally tradable), $z \leq L$. When emission permits are internationally tradable, market clearing in the permit market requires $z+z^{*} \leq L+L^{*}$. If all firms in each country face the same prices for goods, for the factors, $v$, and the externality, then individual profit maximization, together with factor market equilibrium, will lead to GNP maximization, or the revenue function as defined above.
} 
We focus on the symmetric equilibrium; this seems natural given the empirical observation that a significant proportion of intra-industry trade is between similar countries. ${ }^{6}$ To focus on the strategic aspect of policy setting, we assume:

Assumption 1 The aggregate price elasticity of demand for the differentiated good is one.

Lapan and Sikdar (2017), Lemma 1, prove that, given policies and the world prices of goods, opening up to trade in goods increases (decreases) the spending on, and the demand for, the differentiated/tradable good if the price elasticity of demand for the tradable aggregate is greater (less) than one. This result follows since the price index of the differentiated good falls as countries move from autarky to trade. We provide a more general proof of Lapan and Sikdar's Lemma 1 as supplementary material; while they assume that the differentiated good is relatively more pollution intensive, our proof does not use this assumption. Given environmental policies, Assumption 1, in conjunction with the aforementioned Lemma, implies that opening up to trade has no effect on equilibrium prices or output, though it raises welfare due to the 'love of variety' preferences. Aggregate spending on the differentiated goods (hence, total demand for the differentiated goods) will be unaffected by changes in the price aggregator due to opening the economy up to trade. Our results are, thus, driven by strategic policy setting considerations.

\section{Strategic Environmental Policy with Tradable Permits}

Governments simultaneously and non-cooperatively choose their permit levels to maximize own welfare. Denote the world price of a permit as $\tau$. Equilibrium is described by:

$$
\begin{aligned}
& e\left(p, p^{*}, u+\psi\left(z, z^{*}\right)\right)=R(p, \tau)+\tau L, \\
& e^{*}\left(p, p^{*}, u^{*}+\psi^{*}\left(z^{*}, z\right)\right)=R^{*}\left(p^{*}, \tau\right)+\tau L^{*}, \\
& e_{p}(.)+e_{p}^{*}(.)=R_{p}(.), \quad e_{p^{*}}(.)+e_{p^{*}}^{*}(.)=R_{p^{*}}^{*}(.), \\
& z+z^{*}=-R_{\tau}(.)-R_{\tau}^{*}(.) \leq L+L^{*},
\end{aligned}
$$

where Eqs. (2) and (3) stipulate that total expenditure has to equal the sum of total revenue from the sale of goods and emission permits in the home and foreign countries, respectively. We have assumed that the permit revenues are rebated lump-sum to consumers. Equation (4) gives the goods market clearing condition for $X$ and $X^{*}$, while Eq. (5) is the emission permit market clearing condition. If the permit limits bind, $\tau>0$, and Eq. (5) holds with equality.

Differentiating Eq. (2) with respect to $L$ gives us the impact of issuing an additional permit on the home country's welfare:

$$
\begin{aligned}
e_{u} \frac{d u}{d L}= & \underbrace{\left(R_{p}-e_{p}\right) \frac{d p}{d L}}_{\text {exportable TOT effect }}-\underbrace{e_{p^{*}} \frac{d p^{*}}{d L}}_{\text {importable TOT effect }}+\underbrace{\left(L+R_{\tau}\right) \frac{d \tau}{d L}}_{\text {permit revenue effect }} \\
& +\underbrace{\left(\tau-e_{u} \psi_{z}\right) \frac{d z}{d L}}_{\text {domestic emission effect }}+\underbrace{\left(\tau-e_{u} \psi_{z^{*}}\right) \frac{d z^{*}}{d L}}_{\text {leakage effect }},
\end{aligned}
$$

6 Countries are said to be symmetric if they have the same preferences and technology. The functional forms, for example $g($.$) and g^{*}($.$) , will be the same across countries, despite the arguments being different. We use *$ to denote foreign functions for the sake of clarity. Furthermore, symmetry implies that $\psi\left(z, z^{*}\right)=\psi^{*}\left(\tilde{z}^{*}, \tilde{z}\right)$, $\forall z, z^{*}$ s.t. $\tilde{z}^{*}=z$ and $\tilde{z}=z^{*}$. However, despite being symmetric, home and foreign countries produce different varieties, $X$ and $X^{*}$, respectively, of the differentiated good along with the homogeneous numeraire good, $Y$. 
where $\frac{d z}{d L}+\frac{d z^{*}}{d L}=1$. The exportable and importable terms of trade effects depend on the relative pollution intensity of the two varieties of the differentiated goods. The permit revenue effect depends on whether the country is an importer or exporter of emissions permits. If some of the additional permits are used domestically, it increases domestic emissions; this is reflected in the fourth term on the RHS. The leakage effect depends on whether foreign emissions increase as the home country issues more permits and on the public bad nature of pollution, i.e., on the extent of transboundary pollution spillovers. The home country's best response function in terms of $L^{*}$ is derived by setting $\frac{d u}{d L}=0$ in Eq. (6): $J\left(L, L^{*}\right) \equiv \frac{d u}{d L}=0$. Similarly, the foreign country's best response function can be derived as $J^{*}\left(L, L^{*}\right) \equiv \frac{d u^{*}}{d L^{*}}=$ 0 .

Autarky. In autarky, domestic production equals domestic consumption, i.e., $R_{p}()=.e_{p}($.) and $e_{p^{*}}()=$.0 , and foreign pollution is independent of domestic policy, i.e., $\frac{d z^{*}}{d L}=0$. Hence, Eq. (6) implies (since $\frac{d z}{d L}=1$ and $e_{u}>0$ ), $\tau^{a}=e_{u} \psi_{z}$; similarly, $\tau^{a *}=e_{u^{*}}^{*} \psi_{z^{*}}^{*}$. Further, symmetry implies:

$$
\tau^{a}=e_{u} \psi_{z}=e_{u^{*}}^{*} \psi_{z^{*}}^{*}=\tau^{a *} \Rightarrow L^{a}=L^{a *} .
$$

Countries choose permit levels such that the permit prices (equivalent emission taxes) equal the domestic marginal damage from own emissions, i.e., equal to the Pigouvian taxes.

Trade in Goods and Emission Permits. Now, consider the situation in which countries trade goods and emission permits. Countries simultaneously issue emission permits and these permits are traded in an international permit market.

Our assumptions (along with symmetry) imply:

$$
e_{p}(.)+e_{p}^{*}(.) \gtreqless e_{p^{*}}(.)+e_{p^{*}}^{*}(.) \text { as } \quad p^{*} \gtreqless p,
$$

where the LHS and RHS are the total (world) demands for $X$ and $X^{*}$, respectively. Permit trade will equalize permit price $(\tau)$ across countries. In conjunction with symmetry, this implies:

$$
R_{p}(p, \tau) \gtreqless R_{p^{*}}^{*}\left(p^{*}, \tau\right) \text { as } p \gtreqless p^{*},
$$

where the LHS and RHS are the outputs of $X$ and $X^{*}$, respectively. Equations (8) and (9) together imply that $p=p^{*}$ in equilibrium; this is true for all permit issuance levels. Hence, we have:

Proposition 1 When countries pursue trade in emission permits, the prices of different varieties of the differentiated good are equalized under trade irrespective of the number of permits that are issued by each country, i.e., $p=p^{*}, \forall L, L^{*}$.

If permits were not internationally tradable, emissions price in each country would be contingent on the pollution policy (permit levels) in the particular country-hence, for different permit issuances, the prices of the different varieties of the differentiated goods could be different. However, with tradable permits, regardless of the number of permits each country issues, permit price is equalized across countries. In our symmetric setup, this implies that the prices of all factors and pollution are equalized across countries. Thus, the prices of the different varieties of the differentiated good are also equalized regardless of the policy in each country.

Lemma 1 The impact of issuing an additional permit on goods and permit prices depends only on the total number of permits issued and not which country issues the permits, i.e., $\frac{d p}{d L}=\frac{d p}{d L^{*}}=\frac{d p^{*}}{d L}=\frac{d p^{*}}{d L^{*}}$ and $\frac{d \tau}{d L}=\frac{d \tau}{d L^{*}}$. 
The proof is relegated to the "Appendix". Irrespective of whether the home or foreign country issues an additional permit, since the permits are tradable, the impact on prices is the same. This follows since, in our setting, if the permit limits bind, i.e., if Eq. (5) binds, only the total number of permits, $L+L^{*}$, matters and not its composition.

Symmetry implies that:

$$
\frac{d z}{d L}=\frac{d z^{*}}{d L}=\frac{d z}{d L^{*}}=\frac{d z^{*}}{d L^{*}}=\frac{1}{2} .
$$

In equilibrium, the market clearing condition for $X$ implies $\left(e_{p}-R_{p}\right)+e_{p}^{*}=0$, and under symmetry, $e_{p}^{*}=e_{p^{*}}$; hence, market equilibrium implies: $\left(e_{p}-R_{p}\right)=-e_{p^{*}}$. This, along with Lemma $1\left(\frac{d p}{d L}=\frac{d p^{*}}{d L}\right)$, implies that the exportable and importable terms of trade effects cancel out in Eq. (6). Hence, the home country's best-response function can be written as [using $-R_{\tau}=z=\frac{L+L^{*}}{2}$ and Eq. (10)]:

$$
\begin{aligned}
J\left(L, L^{*}\right) & =(L-z) \frac{d \tau}{d L}+\left[\tau-e_{u}\left(\frac{\psi_{z}+\psi_{z^{*}}}{2}\right)\right] \\
& =\left(\frac{L-L^{*}}{2}\right) \frac{d \tau}{d L}+\left[\tau-e_{u}\left(\frac{\psi_{z}+\psi_{z^{*}}}{2}\right)\right]=0 .
\end{aligned}
$$

Similarly, the foreign country's best-response function can be written as:

$$
J^{*}\left(L, L^{*}\right)=\left(\frac{L^{*}-L}{2}\right) \frac{d \tau}{d L^{*}}+\left[\tau-e_{u^{*}}^{*}\left(\frac{\psi_{z^{*}}^{*}+\psi_{z}^{*}}{2}\right)\right]=0 .
$$

Since $\frac{d \tau}{d L}=\frac{d \tau}{d L^{*}}$ (Lemma 1), adding Eqs. (11) and (12), we have the permit price under trade:

$$
\tau=e_{u}\left(\frac{\psi_{z}+\psi_{z^{*}}}{4}\right)+e_{u^{*}}^{*}\left(\frac{\psi_{z^{*}}^{*}+\psi_{z}^{*}}{4}\right) .
$$

If pollution is a pure global public bad, ${ }^{7}$ then eq. (13) implies that the permit price (equivalent emission tax) and permit levels are the same as those under autarky [given by Eq. (7)]:

$$
\tau=e_{u} \psi_{z}=e_{u^{*}}^{*} \psi_{z^{*}}^{*}=\tau^{a} \Rightarrow L=L^{*}=L^{a}=L^{a *} .
$$

Hence, the equivalent emissions tax equals the marginal damage from own emissions (the Pigouvian tax). Note that there is no permit revenue or leakage effect here; since the marginal damage from increased emission in either country is the same, there is no incentive to issue additional permits under trade to be sold on the international permit market.

However, if pollution is not a pure global public bad, i.e., if the marginal damage from local emissions is higher than that from the incidence of transboundary pollution $\left(\psi_{z}>\psi_{z^{*}}\right.$ and $\psi_{z^{*}}^{*}>\psi_{z}^{*}$ ), then Eq. (13) implies ${ }^{8}$ :

$$
\begin{aligned}
e_{u}\left(\frac{\psi_{z}+\psi_{z^{*}}}{2}\right) & =e_{u^{*}}^{*}\left(\frac{\psi_{z^{*}}^{*}+\psi_{z}^{*}}{2}\right)=\tau<\tau^{a}=e_{u} \psi_{z}=e_{u^{*}}^{*} \psi_{z^{*}}^{*} \\
& \Rightarrow L=L^{*}>L^{a}=L^{a *}
\end{aligned}
$$

Hence, relative to autarky, emissions in both countries are higher when there is trade in goods and emission permits. Issuing an additional permit results in lower marginal damage than

\footnotetext{
7 The pure global public nature of pollution implies $\psi_{z}=\psi_{z^{*}}^{*}=\psi_{z^{*}}=\psi_{z}^{*}$, while symmetry implies $e_{u}=e_{u^{*}}^{*}$.

${ }^{8}$ Symmetry implies $e_{u}=e_{u^{*}}^{*}, \psi_{z}=\psi_{z^{*}}^{*}$ and $\psi_{z^{*}}=\psi_{z}^{*}$.
} 
when pollution is a pure global bad since part of the permits are used in the other country and pollution spillovers are not complete. The additional revenue from selling a permit in the international permit market exceeds the marginal damage from increased incidence of transboundary pollution. This tends to increase the number of permits issued by both countries. This incentive is absent when pollution is a pure global public bad since the source of emissions does not matter as the marginal damage is the same irrespective of the origin of pollution.

Lapan and Sikdar (2017), Proposition 3, show that (in a similar setup) with internationally nontradable permits, irrespective of the public good nature of pollution, intra-industry trade leads to higher permit prices and lower pollution relative to autarky. ${ }^{9}$ Hence, we have:

Proposition 2 Suppose countries pursue trade in a differentiated good and emission permits.

- International trade in emission permits always results in higher pollution as compared to internationally nontradable permits.

- If pollution is a pure global public bad, i.e., if the marginal damage from domestic and transboundary pollution is the same, then the permit price under trade equals the domestic marginal damage from own emissions and emissions in both countries are the same under trade as in autarky.

- If pollution is not a pure global public bad, i.e., if the marginal damage from domestic emissions is higher than that from transboundary pollution, then the permit price under trade is lower than the domestic marginal damage from own emissions and emissions in both countries are higher under trade than in autarky.

In Lapan and Sikdar (2017), if, say, the home country lowers the number of nontradable permits under trade relative to autarky, it results in increases in the prices of both the home (exportable) and foreign (importable) varieties of the differentiated good. The former effect dominates and the goods terms of trade effect results in stricter pollution policy under trade; the permit price is found to be higher than the domestic marginal damage from own emissions. However, when emission permits are tradable across countries, there is no differential impact on the prices of the different varieties of the differentiated good as the permits can be used in either country; hence, there is no terms of trade effect. This difference in the goods terms of trade effect drives the result that tradable permits always result in higher pollution than nontradable permits.

Note that if we relax our assumption of symmetry, by continuity, provided countries are sufficiently similar, our results would continue to hold. Hence,

Corollary 1 If countries are sufficiently similar, movement from autarky to trade in goods and emission permits results in higher pollution.

The usual argument that trade in emission permits among countries could increase efficiency and lower pollution may not be applicable once the strategic incentives to distort policies are taken into account; then, permit trade between countries results in higher pollution.

9 Lapan and Sikdar (2017) show that the internationally nontradable permit price under goods trade is $\tau^{N T}=$ $e_{u} \psi_{z}+f\left(R_{p}-e_{p}, e_{p^{*}}\right)$, with $f()>$.0 capturing the net terms of trade effect for goods; $f($.$) is increasing$ in exports of variety $X$ and decreasing in the imports of variety $X^{*}$, i.e., the first and second arguments of $f($.), respectively - see Eq. (22) in their paper. It is straightforward to see that, when pollution is a pure global public bad, $\tau=e_{u} \psi_{z}<e_{u} \psi_{z}+f\left(R_{p}-e_{p}, e_{p^{*}}\right)=\tau^{N T}$. Further, if transboundary pollution spillovers are incomplete (i.e., if $\left.\psi_{z^{*}}<\psi_{z}\right), \tau=e_{u}\left(\frac{\psi_{z}+\psi_{z^{*}}}{2}\right)<e_{u} \psi_{z}<e_{u} \psi_{z}+f\left(R_{p}-e_{p}, e_{p^{*}}\right)=\tau^{N T}$. 


\section{Concluding Remarks}

The initial success of the US $\mathrm{SO}_{2}$ allowance trading system has resulted in a push towards developing an emission permit trading system across countries (for instance, the EU Emissions Trading System for $\mathrm{CO}_{2}$ and the Copenhagen Accord). However, when countries choose their emission allowances non-cooperatively and these permits are internationally tradable (as documented in Kruger et al. (2007) and discussed in the Introduction), strategic incentives result in countries distorting their environmental policies. Using a model of intra-industry trade, we have shown that permit trading results in higher pollution relative to the situation in which permits are not tradable across countries. Further, a successful market-based mechanism is only a first step and subsequent government policies need to be in line with the initial setup. As Schmalensee and Stavins (2013) point out "court decisions and subsequent regulatory responses have led to the virtual collapse of the $\mathrm{SO}_{2}$ market, demonstrating that what the government gives, the government can take away".

To focus on the strategic aspect of policy setting, we assumed that the aggregate price elasticity of demand for the tradable differentiated good is one, which ensures our results are driven by strategic policy setting considerations. Suppose that the differentiated good is relatively more pollution intensive. Then, given policies, opening to trade would increase (decrease) pollution if the price elasticity of demand for the differentiated good is greater (less) than one. The qualitative results are, however, likely to be the same as we have presented. More importantly, there does not seem to be any empirical evidence about the elasticity of demand for such goods.

Open Access This article is distributed under the terms of the Creative Commons Attribution 4.0 International License (http://creativecommons.org/licenses/by/4.0/), which permits unrestricted use, distribution, and reproduction in any medium, provided you give appropriate credit to the original author(s) and the source, provide a link to the Creative Commons license, and indicate if changes were made.

\section{Appendix}

Proof of Lemma 1 Taking the total differential of Eq. (4), we have:

$$
\begin{aligned}
{\left[\left(e_{p p}-R_{p p}\right)+e_{p p}^{*}\right] d p+\left[e_{p p^{*}}+e_{p p^{*}}^{*}\right] d p^{*} } & =R_{p \tau} d \tau, \\
\text { and }\left[e_{p p^{*}}+e_{p p^{*}}^{*}\right] d p+\left[\left(e_{p^{*} p^{*}}^{*}-R_{p^{*} p^{*}}^{*}\right)+e_{p^{*} p^{*}}\right] d p^{*} & =R_{p^{*} \tau}^{*} d \tau
\end{aligned}
$$

Defining $D \equiv\left(R_{\tau \tau}+R_{\tau \tau}^{*}\right)$ and taking the total differential of Eq. (5), we have:

$$
D d \tau=-\left[R_{p \tau} d p+R_{p^{*} \tau}^{*} d p^{*}+d L+d L^{*}\right] .
$$

Define $A_{11} \equiv\left[\left(e_{p p}-R_{p p}\right)+e_{p p}^{*}+\frac{R_{p \tau}^{2}}{R_{\tau \tau}+R_{\tau \tau}^{*}}\right], A_{12}=A_{21} \equiv\left[e_{p p^{*}}+e_{p p^{*}}^{*}+\frac{R_{p \tau} R_{p^{*} \tau}^{*}}{R_{\tau \tau}+R_{\tau \tau}^{*}}\right]$ and $A_{22} \equiv\left[\left(e_{p^{*} p^{*}}^{*}-R_{p^{*} p^{*}}^{*}\right)+e_{p^{*} p^{*}}+\frac{R_{p^{*} \tau}^{* 2}}{R_{\tau \tau}+R_{\tau \tau}^{*}}\right]$. Using Eq. (18) in Eqs. (16) and (17), we have:

$$
\underbrace{\left[\begin{array}{ll}
A_{11} & A_{12} \\
A_{21} & A_{22}
\end{array}\right]}_{\equiv \mathbf{A}}\left[\begin{array}{c}
d p \\
d p^{*}
\end{array}\right]=-\frac{1}{D} \underbrace{\left[\begin{array}{c}
R_{p \tau} \\
R_{p^{*} \tau}^{*}
\end{array}\right]}_{\equiv \mathbf{B}}\left(d L+d L^{*}\right) \Rightarrow\left[\begin{array}{c}
d p \\
d p^{*}
\end{array}\right]=-\frac{\mathbf{A}^{-1} \mathbf{B}}{D}\left(d L+d L^{*}\right) .
$$


Hence, $\frac{d p}{d L}=\frac{d p}{d L^{*}}=-\frac{A_{22} R_{p \tau}-A_{12} R_{p^{*} \tau}^{*}}{D \Delta}$ and $\frac{d p^{*}}{d L}=\frac{d p^{*}}{d L^{*}}=-\frac{A_{11} R_{p^{*} \tau}^{*}-A_{21} R_{p^{*} \tau}^{*}}{D \Delta}$, where $\Delta=|A|=\left(A_{11} A_{22}-A_{12} A_{21}\right)$. Symmetry implies $R_{p \tau}=R_{p^{*} \tau}^{*}$ and $A_{11}=A_{22}$; thus, $\frac{d p}{d L}=\frac{d p}{d L^{*}}=\frac{d p^{*}}{d L}=\frac{d p^{*}}{d L^{*}}$.

Using Eq. (19) in Eq. (18), we have: $d \tau=-\frac{\mathbf{B}^{T}}{D}\left[\begin{array}{c}d p \\ d p^{*}\end{array}\right]-\frac{\left(d L+d L^{*}\right)}{D}=\frac{1}{D}\left[\frac{\mathbf{B}^{T} \mathbf{A}^{-1} \mathbf{B}}{D}-1\right]$ $\left(d L+d L^{*}\right)$, implying $\frac{d \tau}{d L}=\frac{d \tau}{d L^{*}}$.

\section{References}

Antoniou F, Hatzipanayotou P, Koundouri P (2014) Tradable permits vs. ecological dumping when governments act non-cooperatively. Oxf Econ Pap 66:188-208

Armington PS (1969) A theory of demand for products distinguished by place of production. IMF Staff Pap 16:159-176

Benarroch M, Weder R (2006) Intra-industry trade in intermediate products, pollution and internationally increasing returns. J Environ Econ Manag 52:675-689

Bernhofen DM (1999) Intra-industry trade and strategic interaction: theory and evidence. J Int Econ 47:225244

Carbone JC, Helm C, Rutherford TF (2009) The case for international emission trade in the absence of cooperative climate policy. J Environ Econ Manag 58:266-280

Copeland BR, Taylor MS (1995) Trade and transboundary pollution. Am Econ Rev 85:716-737

Dijkstra BW, Manderson E, Lee T-Y (2011) Extending the sectoral coverage of an international emission trading scheme. Environ Resour Econ 50:243-266

Fung KC, Maechler AM (2007) Trade liberalization and the environment: the case of intra-industry trade. J Int Trade Econ Dev 16:53-69

Godal O, Holtsmark B (2011) Permit trading: merely an efficiency-neutral redistribution away from climatechange victims. Scand J Econ 113:784-797

Grubel HG, Lloyd PJ (1975) Intra-industry trade: the theory and measurement of international trade in differentiated products. Wiley, New York

Gürtzgen N, Rauscher M (2000) Environmental policy, intra-industry trade and transfrontier pollution. Environ Resour Econ 17:59-71

Haupt A (2006) Environmental policy in open economies and monopolistic competition. Environ Resour Econ $33: 143-167$

Helm C (2003) International emissions trading with endogenous allowance choices. J Public Econ 87:27372747

Holtsmark B, Sommervoll DG (2012) International emissions trading: good or bad? Econ Lett 117:362-364

Kruger J, Oates WE, Pizer WA (2007) Decentralization in the EU emissions trading scheme and lessons for global policy. Rev Environ Econ Policy 1:112-133

Lapan HE, Sikdar S (2011) Strategic environmental policy under free trade with transboundary pollution. Rev Dev Econ 15:1-18

Lapan HE, Sikdar S (2017) Can trade be good for the environment? J Public Econ Theory 19:267-288

Rauscher M (1997) International trade, factor movements and the environment. Claredon Press, Oxford

Schmalensee R, Stavins RN (2013) The $\mathrm{SO}_{2}$ allowance trading system: the ironic history of a grand policy experiment. J Econ Perspect 21:103-122

Tharakan PKM (1984) Intra-industry trade between the industrial countries and the developing world. Eur Econ Rev 26:213-227 